\title{
The molecular effect of a polymorphic microRNA binding site of Wolfram syndrome 1 gene in dogs
}

Dora Koller ${ }^{1,2,3^{*}}$ (D) Eniko Kubinyi ${ }^{1,3+}$, Zsuzsanna Elek ${ }^{2}$, Helga Nemeth², Adam Miklosi ${ }^{1,3}$, Maria Sasvari-Szekely ${ }^{2}$ and Zsolt Ronai $^{2}$

\begin{abstract}
Background: Although the molecular function of wolframin remains unclear, the lack of this protein is known to cause stress in the endoplasmic reticulum. Some variants in the Wolfram Syndrome 1 gene (WFS1) were associated with various neuropsychiatric disorders in humans, such as aggressiveness, impulsivity and anxiety.

Results: Here we present an in silico study predicting a single nucleotide polymorphism (rs852850348) in the canine WFS1 gene which was verified by direct sequencing and was genotyped by a PCR-based technique. We found that the rs852850348 polymorphism is located in a putative microRNA (cfa-miR-8834a and cfa-miR-1838) binding site. Therefore, the molecular effect of allelic variants was studied in a luciferase reporter system that allowed assessing gene expression. We demonstrated that the variant reduced the activity of the reporter protein expression in an allele-specific manner. Additionally, we performed a behavioral experiment and investigated the association with this locus to different performance in this test. Association was found between food possessivity and the studied WFS1 gene polymorphism in the Border collie breed.
\end{abstract}

Conclusions: Based on our findings, the rs 852850348 locus might contribute to the genetic risk of possessivity behavior of dogs in at least one breed and might influence the regulation of wolframin expression.

Keywords: WFS1, Polymorphism, miRNA, Dog, Behavior

\section{Background}

Investigation of the genetic background of behavior is in the center of interest for more than two decades. Psychogenetic studies of human personality began in 1996 when associations were found between a repeat polymorphism in exon III of the dopamine D4 receptor gene (DRD4) and novelty seeking [1]. Dogs are increasingly applicable models in human psychogenetic studies, not only because they live together with humans in similar

\footnotetext{
* Correspondence: dorakoller91@gmail.com

${ }^{\dagger}$ Dora Koller and Eniko Kubinyi contributed equally to this work.

${ }^{1}$ Comparative Ethology Research Group, MTA-ELTE, Budapest, Hungary

${ }^{2}$ Department of Medical Chemistry, Molecular Biology and

Pathobiochemistry, Semmelweis University, Budapest, Hungary

Full list of author information is available at the end of the article
}

social environment, but they also share various behavioral disorders, such as over-aggression, attention deficit hyperactivity disorder, anxiety and obsessive-compulsive disorder [2].

Compared to human polymorphism data, very few canine polymorphisms can be found in databases. Even though some databases exist which contain polymorphisms in canine genes, usually predicted by in silico methods, they do not have sufficient subject number or do not consider several breeds [3]. Therefore, it is of importance to confirm the existence of predicted polymorphisms by targeted sequencing. Moreover, despite of the rapid progression of genomic approaches, the genetic background of canine behavior is far from completely

(C) The Author(s). 2020 Open Access This article is licensed under a Creative Commons Attribution 4.0 International License, which permits use, sharing, adaptation, distribution and reproduction in any medium or format, as long as you give appropriate credit to the original author(s) and the source, provide a link to the Creative Commons licence, and indicate if changes were made. The images or other third party material in this article are included in the article's Creative Commons licence, unless indicated otherwise in a credit line to the material. If material is not included in the article's Creative Commons licence and your intended use is not permitted by statutory regulation or exceeds the permitted use, you will need to obtain permission directly from the copyright holder. To view a copy of this licence, visit http://creativecommons.org/licenses/by/4.0/ The Creative Commons Public Domain Dedication waiver (http://creativecommons.org/publicdomain/zero/1.0/) applies to the data made available in this article, unless otherwise stated in a credit line to the data. 
explored yet [4]. Several phenotypes were investigated such as dog-directed aggression, owner-directed aggression, nonsocial fear, separation anxiety and touch sensitivity [5-8]. Furthermore, associations between polymorphisms in the dopamine receptor D4 gene (DRD4) and the tyrosine hydroxylase gene $(T H)$ and impulsivity, activity, inattention of German shepherd dogs and Siberian husky dogs; and oxytocin receptor (OXTR) and $\mathrm{mu}(\mu)$ opioid receptor (OPRM1) genes and greeting behavior and human directed social behavior in German shepherd dogs and border collies were published by our group previously [9-12]. However, the previously mentioned studies did not investigate the molecular effects of carrying different alleles.

Several common Wolfram Syndrome 1 gene (WFS1) alleles were shown to associate with various neuropsychiatric disorders [13], such as bipolar depression [14], high risk to attempt suicide and aggression, or with behavioral traits, such as anxiety, impulsivity [15], and impulsive verbal and physical aggression [16] among humans. This gene encodes an endoplasmic reticulum membrane protein (wolframin), present mainly in neurons and pancreatic $\beta$-cells. The function of this protein is not completely understood yet [17], however, it is well known that its malfunction causes an increased stress in the endoplasmic reticulum, leading to the destruction of cell cycle and calcium homeostasis [18]. Rare mutations in the human WFS1 gene, located on human chromosome 4, are responsible for the development of Wolfram syndrome, which is considered monogenic [19]. This disease is a clinical condition with the presence of diabetes insipidus, diabetes mellitus, optic atrophy and deafness [20].

Wolfram syndrome is considered a monogenic disorder, however, behavioral traits associated with polymorphisms in the WFS1 gene are more complex [21]. To understand this complexity, the functional role of these polymorphisms should be investigated for which microRNAs (miRNAs) are suitable candidates. MiRNAs are a family of small, non-coding RNAs that play important regulatory roles in many physiological and disease processes [22]. Although 355 miRNAs are predicted in silico having a putative binding site in the 3'UTR region of the human WFS1 gene (http://zmf.umm.uni-heidelberg.de/apps/zmf/mirwalk/), only a few of them have been confirmed by molecular methods [23]. To understand the role of miRNAs in different physiological processes, it is important to utilize experimental approaches that allow for the detection of miRNA-induced alterations in mRNA expression. Firefly luciferase is commonly used as a reporter to assess the transcriptional activity of target genes in intact cells. After its introduction to the market, the luciferase reporter gene assay was used to examine the regulation of transcriptional activities by promoters and transcription factors [24]. Currently it is also applied for testing the effect of miRNA-mediated, post-transcriptional regulation in target genes by composing a luciferase gene construct containing the predicted miRNA targeting sequence from the target gene (often located in the 3'UTR) [25].

The aim of our study was to investigate if any polymorphism in the WFS1 gene regulates wolframin expression. Particularly, we aimed to demonstrate if there is any locus which is a functional polymorphism. Additionally, we aimed to associate this genetic marker to a behavioral trait in dogs to determine its possible role in the molecular genetics of dog behavior. According to our best knowledge, WFS1 polymorphisms and their role have not been studied in dogs yet. Moreover, this is the first report describing the functional effect of a miRNA binding site polymorphism in WFS1 gene in dogs.

\section{Methods \\ Samples}

In total, 274 animals were included in the study (German shepherd dogs, $n=104$; border collies, $n=83$; Eurasian wolves (Canis lupus), $n=34$; Labrador retrievers, $n=23$; beagles, $n=19$; golden retrievers, $n=11$ ). Buccal samples were collected from the animals as described in [26]. Briefly: the inner surface of the cheek was rubbed with a cotton swab for about $10 \mathrm{~s}$, and the procedure was repeated with a second swab. DNA purification was carried out as desribed earlier for human samples [27]. Typical DNA concentration of the dogs' genomic DNA samples isolated from buccal swabs was around $20 \mathrm{ng} / \mu \mathrm{l}$.

\section{Sequencing}

The dog WFS1 gene sequence was obtained from GenBank (http://www.ncbi.nlm.nih.gov/) and Ensembl (http://www.ensembl.org/) databases, accession numbers were as follows: NC_006595.3 and ENSCAFG000 00001781, respectively. Five sets of PCR primers were constructed by the NCBI/Primer-Blast tool (http://www. ncbi.nlm.nih.gov/tools/primer-blast/). The Qiagen HotStarTaq polymerase kit (Qiagen, Hilden, Germany) was used for PCR amplification. The reaction mixture included $1 \mu \mathrm{M}$ of each primer (Table 1), approximately 5 ng of DNA template, $200 \mu \mathrm{M}$ dNTP, $0.025 \mathrm{U}$ HotStarTaq DNA polymerase, $1 \times$ buffer, and $1 \times$ Q-solution supplied together with the enzyme. The PCR cycle consisted of an initial denaturation at $95^{\circ} \mathrm{C}$ for $15 \mathrm{~min}, 40$ cycles of 1 -min denaturation at $95^{\circ} \mathrm{C}, 1$-min annealing at different temperatures shown in Table 1, a 1-min extension at $72{ }^{\circ} \mathrm{C}$, and a 10 -min final extension at $72^{\circ} \mathrm{C}$. The total volume of the reactions was $20 \mu \mathrm{l}$. The obtained PCR products were cleaned with a Wizard SV Gel and PCR Clean-Up System (Promega A9282 
Table 1 Sequencing primers and annealing temperatures used for PCR amplification of dog WFS1 gene regions

\begin{tabular}{lllll}
\hline Sequencing primers & Forward primer & Reverse primer & Product lenght (base pairs) & $\mathrm{T}_{\mathbf{A}}\left({ }^{\circ} \mathrm{C}\right)$ \\
\hline Primer pair 1 & CACCCCTGCCACATCCGCAA & CGGCCACGTCGACTCCCAAC & 525 & 59 \\
Primer pair 2 & GTCCTGCAGCCCCGGCAATG & GCGACCAGAGGTGTCCGCAG & 531 & 59 \\
Primer pair 3 & GGCCGCGGAGGAGCTATGC & CCACGTCGACTCCCAACGCT & 562 & 60 \\
Primer pair 4 & ACGGCCGCGGAGGAGCTATG & GTTCCTGTGGTGCTGGTGCCC & 537 & 60 \\
Primer pair 5 & CGGAGGAGCTATGCCGCCTGA & GCTGCAGGCAGTTCCTGTGGT & 540 & 60 \\
\hline
\end{tabular}

Madison, Wisconsin, USA) and sequenced with Sanger method (Microsynth AG, Balgach, Switzerland) in both forward and reverse directions with the same PCR primers used for amplification. SNPs were identified by aligning and comparing the sequence data with the Clustal Omega tool (http://www.ebi.ac.uk/Tools/msa/ clustalo).

\section{Genotyping}

The rs852850348 SNP in the dog WFS1 3'UTR was genotyped as follows: PCR amplification was performed with the following primers: 5' GTCCTGCAGCCCCG GCAATG 3' and 5' GCGACCAGAGGTGTCCGCAG $3^{\prime}$. The following thermocycle was used: $95^{\circ} \mathrm{C}$ for 15 min, then 40 cycles of $94{ }^{\circ} \mathrm{C}$ for $1 \mathrm{~min}$, annealing at $58^{\circ} \mathrm{C}$ for $30 \mathrm{~s}$ and $72{ }^{\circ} \mathrm{C}$ for $1 \mathrm{~min}$. The final step was $72^{\circ} \mathrm{C}$ for $10 \mathrm{~min}$. Total reaction volume was $10 \mu \mathrm{l}$. PCR products were incubated for $3-6 \mathrm{~h}$ at $37^{\circ} \mathrm{C}$ in a restriction enzyme mixture consisting of $0.5 \mathrm{U} / \mu \mathrm{l} P \nu u \mathrm{II}$ restriction enzyme (NEB), $1 \times$ BSA and $1 \times$ NEBuffer 3.1 in a total reaction volume of $20 \mu \mathrm{l}$. The digested PCR products were analyzed by conventional submarine agarose gel electrophoresis (Biocenter, Szeged, Hungary), using 1.5\% agarose mixed with $2 \%$ MetaPhor ${ }^{\bullet}$ Agarose gel (Lonza Walkersville, Inc., USA) and visualized by ethidium bromide staining.

\section{Assessment of WFS1 expression Plasmid construction}

A 524 base-pair long segment of the 3' untranslated region (3'UTR) of the WFS1 gene was amplified by PCR using a DNA-sample of a dog with known (homozygous AA) genotype for the previously identified SNP. We used the following primers: 5' CGT TCC GAG CTC CCG TGT GAG CCC GTC C 3' (the SacI restriction enzyme site is underlined) forward and 5' AAA TAA ACG CGT GAC CAG CAG TAG GTT TCG TGA 3' (the $M l u I$ restriction enzyme site is underlined) reverse primers. The PCR products were digested with $\mathrm{SacI}$ and $M l u \mathrm{I}$ and were cloned downstream of the firefly luciferase gene in a pMIR-Report plasmid (pMIR-REPORT miRNA Expression Reporter Vector System; ABI) by T4 DNA ligase (New England BioLabs, Ipswich, Massachusetts, USA) using standard protocols. The construct with the $\mathrm{G}$ allele was generated by Quick Change
Lightning Site-Directed Mutagenesis Kit (Agilent Technologies, Santa Clara, USA). A control construct was used containing a different insert with the same length lacking any sequence complementary to miR-8834a and miR-1838. All constructs were confirmed by Sanger sequencing.

\section{miRNA binding assay}

An in silico study was performed to identify miRNA binding sites in the dog WFS1 gene. Canine mature miRNA sequences were downloaded from the miRBase database (http://www.mirbase.org/). Based on the sequence of the WFS1 3' UTR, two miRNAs (cfa-miR8834a and cfa-miR-1838) were suggested to have a putative interaction with the mRNA in close proximity to the rs852850348 locus. The Human Embryonic Kidney cell line (HEK293T) was cultured in DMEM medium (Gibco Invitrogen, Carlsbad, California, USA), supplemented with $10 \%$ bovine fetal serum (Lonza Walkersville, Inc., USA). The cells were maintained at $37{ }^{\circ} \mathrm{C}$ in a $5 \% \mathrm{CO}_{2}$ atmosphere. For miRNA assays the cells were seeded into 24-well plates and were incubated for $24 \mathrm{~h}$ before transfection. Subsequently, $0.05 \mu \mathrm{g}$ of the luciferase reporter construct were cotransfected with $0.2 \mu \mathrm{g} \beta$-galactosidase plasmid (Ambion, Kaufungen, Germany) and 5 pmol of cfa-miR1838 and cfa-miR8834a (Thermo Fisher Scientific, Waltham, Massachusetts, USA) using Lipofectamine 2000 (Invitrogen, Carlsbad, California, USA) according to the manufacturer's protocol. Cells were collected $48 \mathrm{~h}$ after transfection, washed with PBS, then extracted by three consecutive freezethaw cycles and subsequent centrifugation. Supernatants were used for enzyme activity measurements. Luciferase activity was measured by adding $60 \mu$ l Luciferin reagent (Promega Corporation, Madison, Wisconsin USA); 0.16 $\mathrm{mg} / \mathrm{ml}$ Luciferin K, $20 \mathrm{nM}$ Tricine, $2.6 \mathrm{nM}$ MgSO4, 0.1 nM Na2EDTA, $33.3 \mathrm{nM}$ DTT, $0.27 \mathrm{nM} \mathrm{Li3CoA} \mathrm{and}$ $0.53 \mathrm{nM} \mathrm{Na2ATP)}$ to $12 \mu \mathrm{l}$ of each cell extract. Luminescence was measured using a Varioskan multiwell plate reader (Thermo Fisher Scientific, Waltham, Massachusetts, USA). Values for luciferase activity were normalized to $\beta$-galactosidase activity (measured by standard protocol using the same Varioskan plate reader in photometry mode). Each experiment was 
independently repeated three times, and each sample was studied in triplicate.

\section{Phenotypic measurement}

Only breeds with at least 60 individuals have been included in the analysis, i.e. border collies and German shepherd dogs. The number of border collies with complete genotype, age and sex data was 64 (mean age = 4, age range: $1-9$ years, male/female $=28 / 36$ ); in case of German shepherd dogs the respective sample size was 72 (mean age $=3$, age range: $1-8$ years, male/female $=$ 40/32). The studied dogs were individually tested in an undisturbed park in a bone take away test [28]. In the test a bone (cooked humerus of a swine) was given to the dog by the owner. When the dog was chewing the bone, the experimenter, wearing an artificial hand, approached the dog, touched the back and head of the dog, put the hand on the bone then pulled away the bone with a string attached to it. We measured at which phase the experimenter could take away the bone from the dog ('Bone possessivity score'): when the artificial hand: was on the back of the dog (score 0); was on the bone (score 1); moved the bone (score 2); pulled away the bone from the dog (score 3 ). The dog was on a leash in this test, tethered to a tree in order to avoid an attack on the experimenter (Fig. 1).

\section{Statistical analyses}

The Hardy-Weinberg equilibrium (HWE) for genotype distributions was assessed by $x^{2}$-test. No significant difference $(p>0.05)$ could be observed between the measured and expected genotype frequencies in each groups separately for the investigated SNP.

The comparison of genotype frequencies among the 5 dogs breeds and the Eurasian wolves was performed by $x^{2}$-tests. ANOVA of the luciferase assays was performed using SPSS software (version 17.0). $P$ values lower or

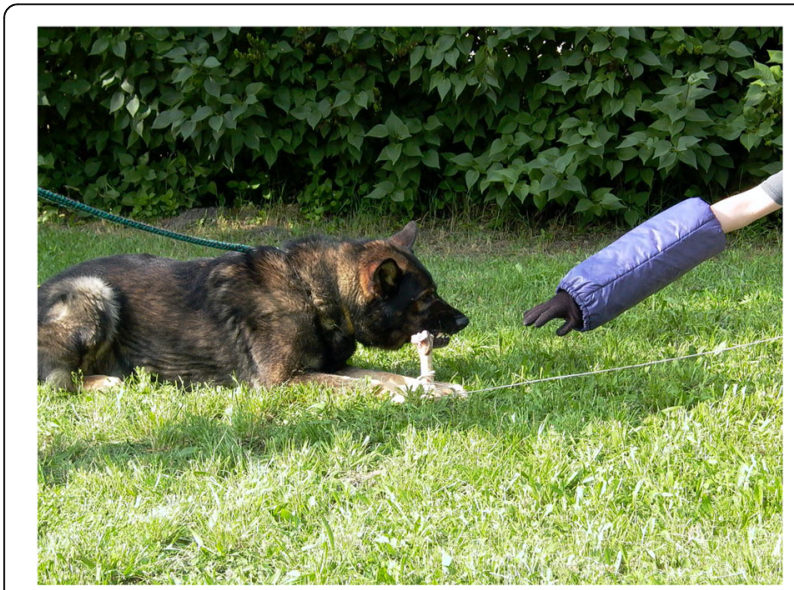

Fig. 1 Bone take away test. Photo: courtesy of Judit Vas equal than 0.05 were considered significant. Association between WFS1 rs852850348 and behavior was assessed by Generalized Linear Model (ordinal logistic). Sex (male, female), genotype (AA, AG, GG) were used as factors and age as covariate in the model. We analyzed the inter-rater reliability and test-retest reliability of the behavior in case of 14 dogs (independent sample) using two-way random intraclass correlation, looking for absolute agreement between average measures.

\section{Results}

In silico determination of rs852850348, cfa-miR-1838 and cfa-miR-8834a

A bibliographic review was carried out looking for candidates. Two DNA and 1 miRNA databases were used. Altogether, 11 SNP candidates were considered for analysis in the 3'UTR region of the dog WFS1 gene. Amongst them, 1 resulted convenient - rs852850348 with the highest minor allele frequency of 0.35 observed in any population. Additionally, based on miRBase database, it was a putative miRNA binding site of two miRNAs, cfa-miR-1838 and cfa-miR-8834a.

\section{Sequencing}

Sanger sequencing of the dog WFS1 gene 3' UTR region (1084 basepairs downstream the stop codon) verified the predicted rs852850348 A $>$ G polymorphism in position 33 of the 3' UTR as shown in Fig. 2. Additionally, Fig. 2 demonstrates the sequence alignment of cfa-miR-1838 and cfa-miR-8834a and their binding sites in the WFS1 mRNA with the "A" and "G" allele, respectively. It shows that the rs852850348 SNP is located 1 base pair next to the binding sites of the seed sequence of these microRNAs.

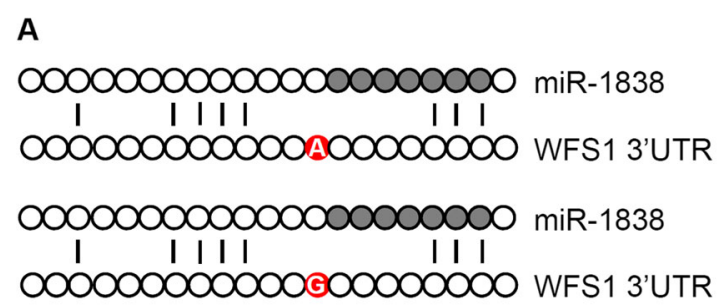

B
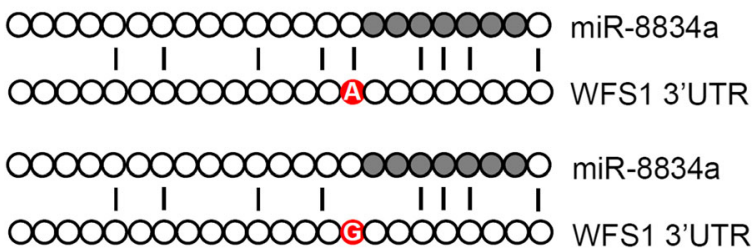

Fig. 2 Sequence alignment of cfa-miR-1838 (Panel a), and cfa-miR8834 a (Panel b) microRNAs and their putative binding sites in the A and $\mathrm{G}$ allele of the WFS1 gene 
The seed sequence of miRNAs is shown in grey and the rs852850348 locus in red. Vertical lines represent complementary nucleotides between miRNA and mRNA.

\section{Genotyping}

A genotyping method was designed for the analysis of rs852850348 using a PCR-RFLP technique. In case of "A" allele, the PvuII enzyme digested the PCR product to three fragments with different lengths $(334+148+46$ $\mathrm{bp})$, however, the sequence with "G" allele provided only two products $(334+194 \mathrm{bp})$. The completion of restriction digestion were controlled by the 334 base pair-long fragment produced by a control cleavage site independent from the polymorphism (Fig. 3a). The obtained DNA fragments were detected by horizontal gel electrophoresis (Fig. 3b).

Using the above method, rs852850348 genotypes of 240 privately owned dogs from 5 different breeds and 34 wolves were determined, and the results are presented in Table 2 and Fig. 3. In most breeds the $G$ allele was the minor allele with a variable frequency from 13 to $47 \%$, except for golden retrievers and beagles where its frequency rised up to $55 \%$ (Table 2). In accordance with the measured allele frequencies, genotype distribution showed also a variable picture (Fig. 4). The AA genotype was the most frequent among Labrador retrievers and less frequent among beagles.

\section{The impact of rs852850348 on luciferase signal}

The molecular impact of rs852850348 SNP was analyzed by in vitro miRNA assay. As predicted by the miRBase database, two miRNAs were identified having a possible role in altering the gene expression. The entire 3'UTR region (524 base pairs) of the WFS1 gene with the rs852850348 "A" allele variant was subcloned into a pMIR-Report luciferase reporter vector. Subsequently,
Table 2 Allele frequencies of rs852850348 among the six subgroups

\begin{tabular}{lll}
\hline & Allele A & Allele G \\
\hline Border collie & 0.58 & 0.42 \\
German shepherd & 0.68 & 0.32 \\
Golden retriever & 0.45 & 0.55 \\
Labrador retriever & 0.87 & 0.13 \\
Beagle & 0.44 & 0.55 \\
Wolf & 0.53 & 0.47 \\
\hline
\end{tabular}

the construct with the " $G$ " allele at the rs 852850348 locus was created by site directed mutagenesis. Moreover, a construct without any binding site of cfa-miR8834a and cfa-miR-1838 (referred to as "control") was also prepared.

Cotransfection of miR-8834a and the reporter construct containing the "A" allele of the rs852850348 SNP showed the lowest level of relative luciferase activity (47.15\% of the "Control"). When miR-8834a was coinfected with the construct carrying "G" allele, $24,85 \%$ of increase was observed in relative luciferase activity comparing to the construct with "A" allele ( $72 \%$ of the control). Although the rs852850348 polymorphism is not located in the seed sequence of the miRNAs (see Fig. 1), it is only one base pair adjacent to the seed sequence in both cases. Nonetheless, significant changes $(p=0.029)$ in luciferase activity were detected between the construct with an "A" and a "G" allele in the presence of miR-8834a, demonstrating that the mRNA-miRNA interaction was weaker in the presence of " $G$ " allele. In addition, the "control" construct without a binding site of cfa-miR-8834a and cfa-miR-1838 resulted in the highest luciferase activity in the presence of cfa-miR-8834a. Additionally, significant changes were found between the construct containing " $\mathrm{A}$ " allele and the control $(p=$ 0.022) (Fig. 5a).

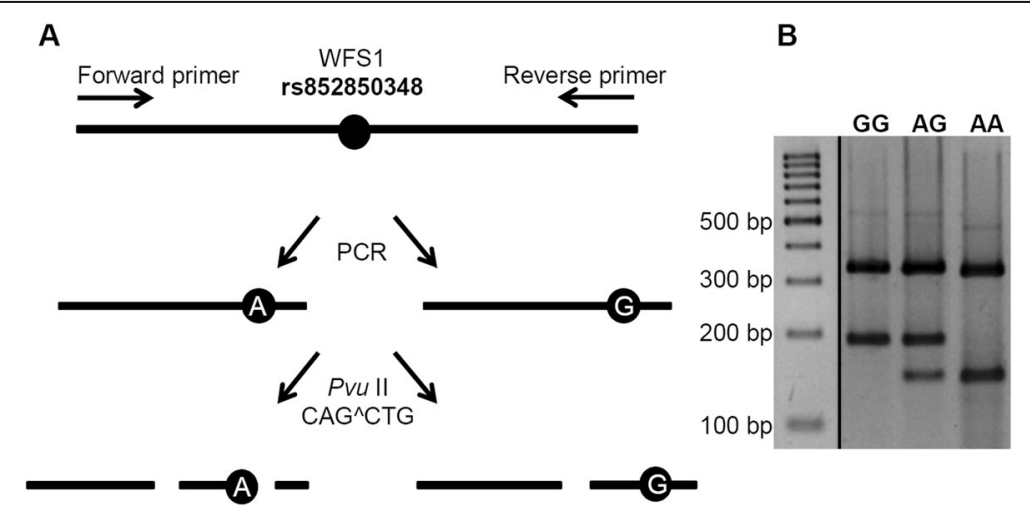

Fig. 3 Genotyping of rs852850348 SNP by restriction digestion of PCR amplicons. Panel a shows the principle of the applied genotyping method. Amplicons of A allele were digested with the Pvull enzyme into three fragments with different lengths, while in case of $\mathrm{G}$ allele only 2 fragments were generated. Panel $\mathbf{b}$ shows the separated fragments of various genotypes as detected by horizontal agarose gel electrophoresis 


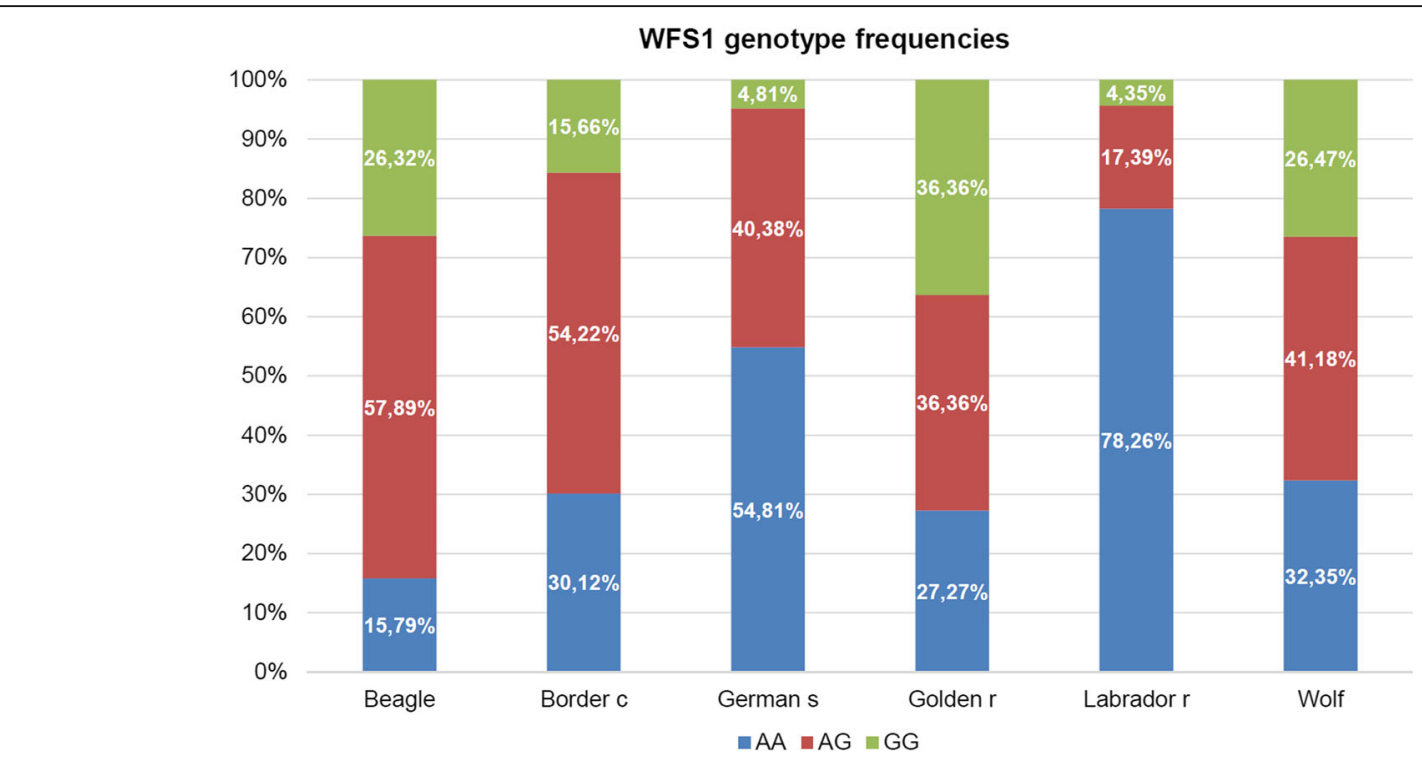

Fig. 4 Variations in rs852850348 genotype distribution among the six subgroups

Application of cfa-miR-1838 did not result in a significant decrease $(p=0.074)$ in relative luciferase level, and no significant differences were found between the relative luciferase activity of the allelic variants (Fig. 5b).

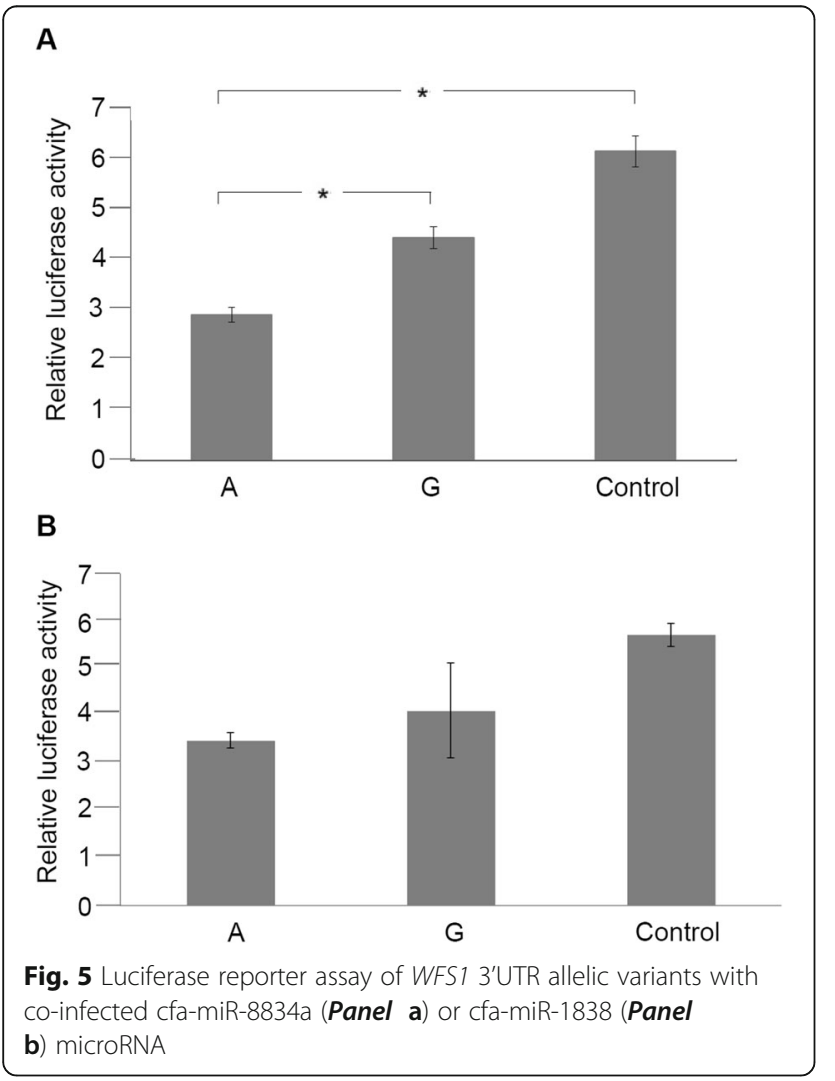

Figure 6 shows the potential functional consequence of this polymorphism when miR8834a binds to the 3'UTR of the dog WFS1 gene.

The entire 3' UTR region of the canine WFS1 gene was subcloned into the pMIR luciferase riporter vector. Transient transfection were performed in HEK293 cells (for details, see Methods section). Luciferase activity values normalized to $\beta$-galactosidase activity were measured, Panel A represents average \pm SD values of three independent experiments in case of co-transfection with cfa-miR-8834a. (" $p<0.05)$. The "A" luciferase construct harbored the rs852850348 A allele, whereas the "G" contained the rs852850348 G variant. "Control" construct had a different DNA-insert with the same length lacking any sequence complementary to cfa-miR-8834a. Panel B demonstrates average \pm SD values of three independent experiments in case of cfa-miR-1838 co-transfection. The circumstances are the same as described before.

\section{Gene-behaviour association study}

Both the inter-rater reliability and the test-retest reliability were satisfactory $(\mathrm{ICC}=0.704$ and 0.872 , respectively, $N=14$ ).

The Generalized Linear Model has not revealed associations between the 'Bone possessivity score' and WFS1 genotypes in the German shepherd dogs. However, in border collies, homozygote GG individuals were less inclined to leave the bone (i.e. they were more possessive) than homozygote AA dogs (Wald Chi square $=6.379$, $\mathrm{df}=2, p=0.041$, Fig. 7). Sex and age had no significant effect on the behaviour. Bone possessivity was not linked to aggressivity, as only 4 dogs growled and 2 attempted to bite during the test. The detailed data of the gene- 

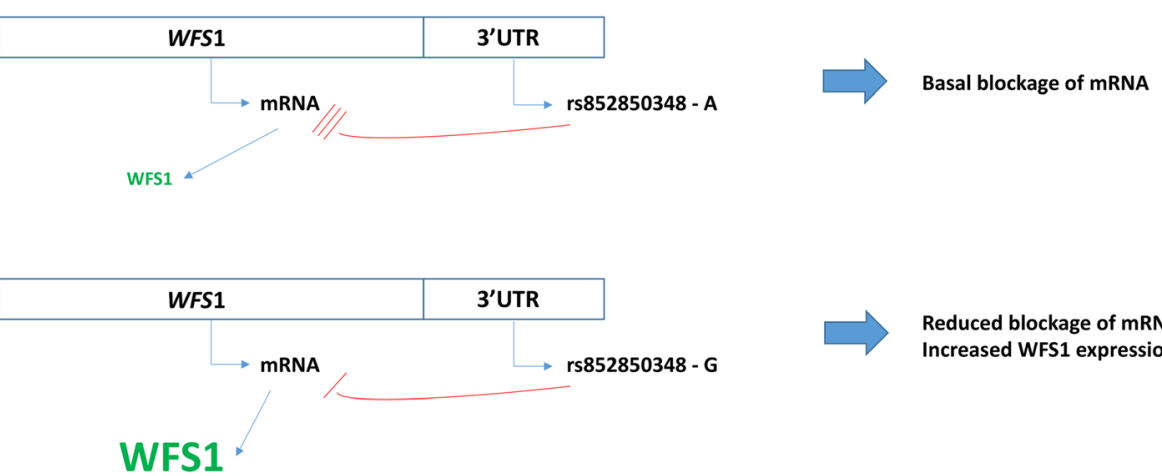

Reduced blockage of mRNA Increased WFS1 expression

\section{WFS1}

Fig. 6 The possible functional role of the WFS1 rs852850348 SNP

behavior association study are available in the Supplementary material.

\section{Discussion}

Very few canine polymorphisms can be found in databases compared to human polymorphism data. These few polymorphisms in databases are usually predicted by in silico methods. For this reason, first a bibliographic review was carried out for SNP candidates with high allele frequency and having a putative miRNA binding site. Previous studies also follow this study design when analyising dog polymorphisms being miRNA binding sites [29]. It is of importance to confirm the existence of in silico predicted SNPs in databases to be able to create a comprehensive database for dogs similar to other organisms.

It has recently been demonstrated that miRNAs play a crucial role in the regulation of protein synthesis, and polymorphisms located in the 3'UTR might alter the binding efficiency of miRNAs contributing to the fine tuning of this regulation. Several miRNA studies have been performed in the last couple of years in humans, mostly in clinical subjects [30-32] but there are some available data with behavioral aspects [3335] as well. Behavioral traits and their connection with miRNAs were also investigated in our laboratory previously [16, 36, 37].

Although some miRNAs were proven to have a binding site in the 3'UTR of different canine genes [22], the functional effect of these miRNAs are still mostly unidentified, and data are available practically only in clinical settings [38-40]. The miRBase database (http:// mirbase.org/) provides the sequence of $502 \mathrm{dog}$ miRNAs, which are annotated in the dog genome (ftp://mirbase.org/pub/mirbase/CURRENT/genomes/cfa.gff3). A publication of an improved canine genome build, canFam3.1 [41] offers a chance to improve this knowledge: previously annotated dog miRNAs were validated and

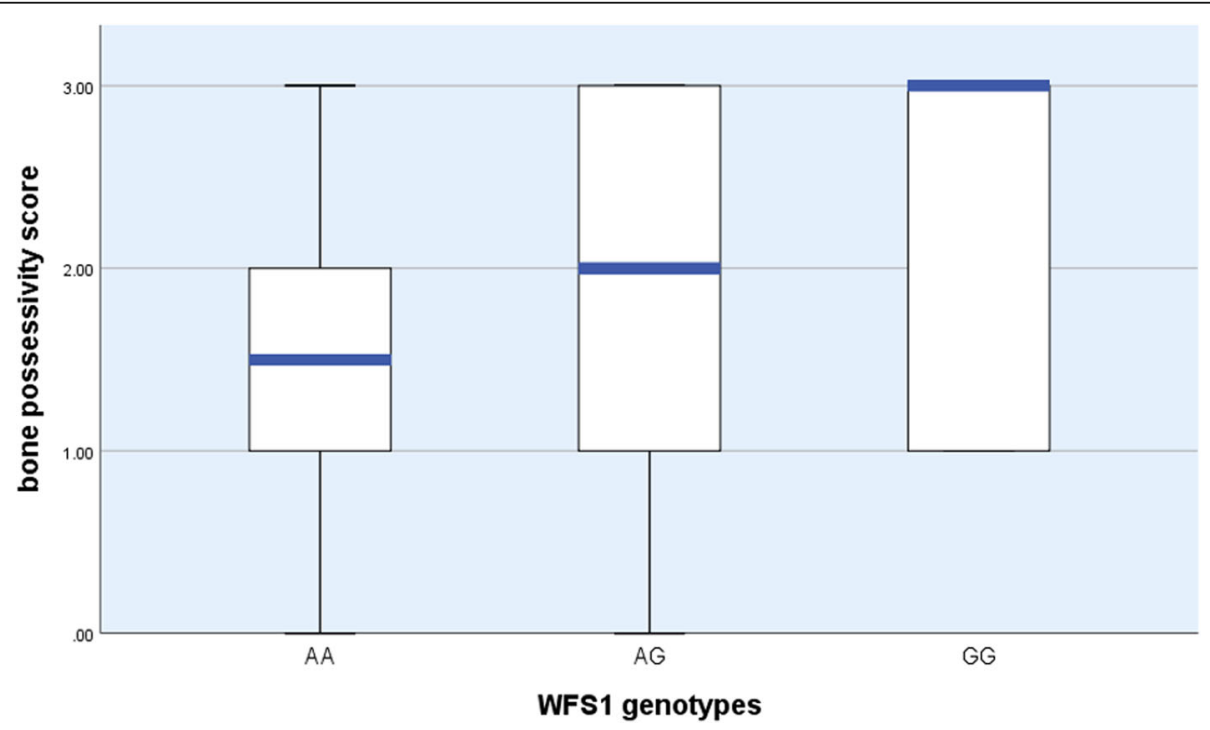

Fig. 7 WFS1 gene-behaviour associations in border collie dogs 
new miRNA sites were identified based on canFam3.1 genome assembly and RNA sequencing data [42]. According to our best knowledge, we are the first to report the functional effect of a SNP influencing the efficiency of microRNA binding in canine WFS1 gene associated with behavioral traits.

The 3'UTR of the WFS1 gene containing the rs 852850348 SNP was investigated by in vitro luciferase reporter system. We observed that the expression of the reporter protein was significantly lower in the presence of the "A" allele compared to the "G" allele at the rs852850348 locus. This finding was of especial interest as the studied SNP was not located in the predicted seed sequence of the cfa-miR-8834a miRNA. This result confirms that although nucleotides at position 2 to 8 are crucial in miRNA-mRNA interaction, further bases of the mature miRNA can also influence this effect [43].

Please note, that the rs852850348 SNP site flanked the seed region. "A" allele is the major allele of rs 852850348 SNP (http://www.ensembl.org/). Therefore, carrying the mutated alelle ("G") does not result in high mRNAmiRNA interaction. Our results confirm the hypothesis that miRNAs usually negatively regulate protein expression in case of carrying wild type genotype [44]. However, the construct containing "G" allele showed also reduced luciferase activity compared to the control. This result suggests that one base pair change does not cause complete mRNA-miRNA dissociation. A similar finding was published by our laboratory previously [45]. The rs1046322 SNP in the 3'UTR of the human WFS1 gene was also examined as putative miRNA binding site polymorphism. Its functional effect was demonstrated in a luciferase reporter system: the minor "A" allele showed lower repression compared to the major " $G$ " allele, if coexpressed with miR-668 [16], similar to our results. Nothwithstanding, the rs852850348 SNP might be in the seed region of another, unknown miRNA. Therefore, the underpining molecular mechanism needs further studies.

Although in silico sequence alignment suggested the putative role of cfa-miR-1838 as well, it could not be confirmed by our luciferase reporter system. Neither significant decrease when applying this miRNA, nor any difference between the effect of the two allelic variants could be detected. These results suggest that this miRNA does not have a role in regulating WFS1 expression.

Our association study suggests that the food possessivity behaviour might have genetic background in some breeds. Border collie dogs carrying GG genotype were more food possessive than dogs with AA genotypes. Food possessivity is often linked to possessive aggression, involving growling, baring the teeth, snapping, or biting when the dog possesses an object (food, bone, toy) and someone (family, stranger, animal) approaches and/or attempts to take it away [46, 47]. However, food possessivity was unrelated to aggression in our test, as only a few dogs growled or attempted to bite. The lack of association of bone possessivity to possessive agression in our study could be due to the low sample size, the unfamiliarity of the situation for the dogs, or the specific characteristics of the Border collie breed.

Wolframin is an endoplasmic reticulum membrane protein. Its function is not completely understood yet, however, its malfunction induces endoplasmic reticulum stress [18]. Endoplasmic reticulum stress activates the unfolded protein response and mediates the pathogenesis of psychiatric diseases when the damage occurs in the hippocampus, the amygdala and striatum [48], where wolframin is greatly present [17]. Therefore, food possession in dogs could be partially due to the polymorphism of the WFS1 gene.

\section{Conlusions}

In conclusion, our study suggests that cfa-miR-8834a regulates the dog WFS1 protein expression, especially when carrying the major " $\mathrm{A}$ " allele of rs 852850348 SNP located in the 3'UTR. Due to the observed biological effect, this locus is not a genetic marker only, but a functional polymorphism, suggesting that the modulation of WFS1 expression might be an important factor in the molecular genetics of dog behavior. Additionally, this SNP might contribute to the genetic background of food possessivity behavior in dogs.

\section{Limitations of the study}

The participating dogs vary in number and include 5 different breeds. Dogs are genetically diverse despite of being the same species. However, even though the breeds are not entirely homogeneous, only a small number of genes account for different phenotypes. Therefore, distinct dog breeds can be analysed together, however, the results have to be considered with caution.

\section{Supplementary information}

Supplementary information accompanies this paper at https://doi.org/10. 1186/s12863-020-00879-7.

\section{Additional file 1.}

\section{Abbreviations}

3'UTR: 3' untranslated region; DMEM: Dulbecco's Modified Eagle Medium; DRD4: Dopamine D4 receptor gene; HEK293T: Human Embryonic Kidney cell line; HWE: Hardy-Weinberg equilibrium; miRNA: microRNA; mRNA: Messenger RNA; OPRM1: Mu ( $\mu$ ) opioid receptor; OXTR: Oxytocin receptor gene; PBS: Phosphate-Buffered Saline; PCR: Polymerase chain reaction; SNP: Single nucleotide polymorphism; TH: Tyrosine hydroxylase gene; WFS1: Wolfram syndrome 1 gene 


\section{Acknowledgments}

The authors are grateful to Judit Vas, Borbála Turcsán, and Anna Kis for their help in conducting the behavioral experiment and to Pablo Zubiaur for his valuable comments.

\section{Authors' contributions}

Conceived and designed the experiments: DK, ZsR, EK, AM. Performed the experiments: DK, HN, ZsE, EK. Analyzed the data: DK, ZsR, EK. Contributed reagents/materials/analysis tools: HN. Wrote the paper: DK, ZsR, MS, EK. All authors have read and approved the manuscript.

\section{Funding}

This work has been supported by grants to MS (OTKA (Országos Tudományos Kutatási Alapprogramok) ANN 107726), AM (MTA (Hungarian Academy of Sciences) 01 031) and EK (OTKA K84036, Bolyai Foundation). This project has received funding from the European Research Council (ERC) under the European Unions Horizon 2020 research and innovation programme (Grant Agreement No. 680040).

\section{Availability of data and materials}

The dataset supporting the conclusions of this article is included within the article (and its additional file). The datasets generated and/or analysed during the current study are available in the GenBank (NC_006595.3), the Ensembl (ENSCAFG00000001781), the miRbase (MI0027920, MI0008044) and the dogSD (cfa6804527) repositories.

\section{Ethics approval and consent to participate}

Non-invasive studies on dogs can be performed without any special permission in Hungary by the University Institutional Animal Care and Use Committee (UIACUC, Eötvös Loránd University, Hungary). The currently operating Hungarian law "1998. évi XXVIII. Törvény" - the Animal Protection Act - gives the definition of experiments on animals in the 9th point of its 3rd paragraph (3. §/9.). According to this definition, the presented, noninvasive observational study is not considered as an animal experiment. The owners volunteered to participate and provided written consent for DNA analysis and behavioral tests of dogs.

\section{Consent for publication}

Not applicable.

\section{Competing interests}

The authors declare no conflict of interest.

\section{Author details}

${ }^{1}$ Comparative Ethology Research Group, MTA-ELTE, Budapest, Hungary. ${ }^{2}$ Department of Medical Chemistry, Molecular Biology and Pathobiochemistry, Semmelweis University, Budapest, Hungary. ${ }^{3}$ Department of Ethology, ELTE Eötvös Loránd University, Budapest, Hungary.

Received: 13 April 2020 Accepted: 29 June 2020

Published online: 28 July 2020

\section{References}

1. Ebstein RP, Novick O, Umansky R, et al. Dopamine D4 receptor (D4DR) exon III polymorphism associated with the human personality trait of novelty seeking. Nat Genet. 1996;12(1):78-80. https://doi.org/10.1038/ng0196-78.

2. Overall KL. Natural animal models of human psychiatric conditions: assessment of mechanism and validity. Prog Neuro-Psychopharmacol Biol Psychiatry. 2000;24(5):727-76. https://doi.org/10.1016/S02785846(00)00104-4.

3. Bai B, Zhao W-M, Tang B-X, et al. DoGSD: the dog and wolf genome SNP database. Nucleic Acids Res. 2015;43(D1):D777-83. https://doi.org/10.1093/ nar/gku1174.

4. Hall NJ, Wynne CDL. The canid genome: behavioral geneticists' best friend?: The canid genome and behavior. Genes Brain Behav. 2012;n/a-n/a. https:// doi.org/10.1111/j.1601-183X.2012.00851.x.

5. Zapata I, Serpell JA, Alvarez CE. Genetic mapping of canine fear and aggression. BMC Genomics. 2016;17:1-20. https://doi.org/10.1186/s12864016-2936-3.
6. Konno A, Inoue-Murayama M, Hasegawa T. Androgen receptor gene polymorphisms are associated with aggression in Japanese Akita Inu. Biol Lett. 2011;7(5):658-60. https://doi.org/10.1098/rsbl.2011.0087.

7. Lit L, Belanger JM, Boehm D, et al. Characterization of a dopamine transporter polymorphism and behavior in Belgian Malinois. BMC Genet. 2013;14:45. https://doi.org/10.1186/1471-2156-14-45.

8. Våge J, Wade C, Biagi T, et al. Association of dopamine- and serotoninrelated genes with canine aggression. Genes Brain Behav. 2010;9(4):372-8. https://doi.org/10.1111/j.1601-183X.2010.00568.X.

9. Wan M, Hejjas K, Ronai Z, et al. DRD4 and TH gene polymorphisms are associated with activity, impulsivity and inattention in Siberian husky dogs. Anim Genet. 2013;44(6):717-27. https://doi.org/10.1111/age.12058.

10. Kubinyi E, Vas J, Hejjas K, et al. Polymorphism in the tyrosine hydroxylase (TH) gene is associated with activity-impulsivity in German shepherd dogs. PLoS One. 2012;7(1):1-6. https://doi.org/10.1371/journal.pone.0030271.

11. Kubinyi E, Bence M, Koller D, et al. Oxytocin and opioid receptor gene polymorphisms associated with greeting behavior in dogs. Front Psychol. 2017;8:1520. https://doi.org/10.3389/fpsyg.2017.01520.

12. Kis A, Bence M, Lakatos G, et al. Oxytocin Receptor Gene Polymorphisms Are Associated with Human Directed Social Behavior in Dogs (Canis familiaris). Claret M, ed. PLoS One. 2014;9(1):e83993. doi:https://doi.org/10. 1371/journal.pone.0083993.

13. Swift RG, Perkins DO, Chase CL, Sadler DB, Swift M. Psychiatric disorders in 36 families with Wolfram syndrome. Am J Psychiatry. 1991;148(6):775-9. https://doi.org/10.1176/ajp.148.6.775.

14. Xavier J, Bourvis N, Tanet A, et al. Bipolar Disorder Type 1 in a 17-Year-Old Girl with Wolfram Syndrome. J Child Adolescent Psychopharmacol. 2016;XX (Xx):cap.2015.0241. doi:https://doi.org/10.1089/cap.2015.0241.

15. Sequeira A, Kim C, Seguin $M$, et al. Wolfram syndrome and suicide: evidence for a role of WFS1 in suicidal and impulsive behavior. Am J Med Genet B Neuropsychiatr Genet. 2003;119B(1):108-13. https://doi. org/10.1002/ajmg.b.20011.

16. Kovacs-Nagy R, Elek Z, Szekely A, Nanasi T, Sasvari-Szekely M, Ronai Z. Association of aggression with a novel microRNA binding site polymorphism in the wolframin gene. Am J Med Genet B Neuropsychiatr Genet. 2013;162(4):404-12. https://doi.org/10.1002/ajmg.b.32157.

17. Inoue $H$, Tanizawa $Y$, Wasson J, et al. A gene encoding a transmembrane protein is mutated in patients with diabetes mellitus and optic atrophy (Wolfram syndrome). Nat Genet. 1998;20(2):143-8. https://doi.org/10.1038/2441.

18. Philbrook C, Fritz E, Weiher H. Expressional and functional studies of Wolframin, the gene function deficient in Wolfram syndrome, in mice and patient cells. Exp Gerontol. 2005;40(8-9):671-8. https://doi.org/10.1016/j. exger.2005.06.008.

19. Khanim F, Kirk J, Latif F, Barrett TG. WFS1/wolframin mutations, Wolfram syndrome, and associated diseases. Hum Mutat. 2001;17(5):357-67. https:// doi.org/10.1002/humu.1110.

20. Barrett TG, Bundey SE. Wolfram (DIDMOAD) syndrome. J Med Genet. 1997; 34(10):838-41. https://doi.org/10.1136/jmg.34.10.838.

21. Koido K, Köks S, Nikopensius T, et al. Polymorphisms in wolframin (WFS1) gene are possibly related to increased risk for mood disorders. Int J Neuropsychopharmacol. 2005;8(2):235-44. https://doi.org/10.1017/ S1461145704004791.

22. Ambros $V$. The functions of animal microRNAs. Nature. 2004;431(7006):3505. https://doi.org/10.1038/nature02871.

23. Dweep H, Sticht C, Pandey P, Gretz N. MiRWalk - database: prediction of possible miRNA binding sites by "walking" the genes of three genomes. J Biomed Inform. 2011;44(5):839-47. https://doi.org/10.1016/j.jbi.2011.05.002.

24. de Wet JR, Wood KV, DeLuca M, Helinski DR, Subramani S. Firefly luciferase gene: structure and expression in mammalian cells. Mol Cell Biol. 2015;7(2): 725-37. https://doi.org/10.1128/mcb.7.2.725.

25. Campos-Melo D, Droppelmann CA, Volkening K, Strong MJ. Comprehensive luciferase-based reporter gene assay reveals previously masked upregulatory effects of miRNAs. Int J Mol Sci. 2014;15(9):15592-602. https://doi. org/10.3390/ijms150915592.

26. Hejjas K, Vas J, Kubinyi E, Sasvari-Szekely M, Miklosi A, Ronai Z. Novel repeat polymorphisms of the dopaminergic neurotransmitter genes among dogs and wolves. Mamm Genome. 2007;18(12):871-9. https://doi.org/10.1007/ s00335-007-9070-0.

27. Kotyuk E, Keszler G, Nemeth N, Ronai Z, Sasvari-Szekely M, Szekely A. Glial cell line-derived Neurotrophic factor (GDNF) as a novel candidate gene of 
anxiety. PLoS One. 2013;8(12):1-8. https://doi.org/10.1371/journal.pone 0080613.

28. Klausz B, Kis A, Persa E, Miklósi Á, Gácsi M. A quick assessment tool for human-directed aggression in pet dogs. Aggress Behav. 2014;40(2):178-88. https://doi.org/10.1002/ab.21501.

29. Holder A, Jones G, Soutter F, Palmer DB, Aspinall R, Catchpole B. Polymorphisms in the canine IL7R $3^{\prime} U T R$ are associated with thymic output in Labrador retriever dogs and influence post-transcriptional regulation by microRNA 185. Dev Comp Immunol. 2018;81:244-51. https://doi.org/10.1016/j.dci.2017.12.008.

30. Zhang $L, X u Y$, Jin $X$, et al. A circulating miRNA signature as a diagnostic biomarker for non-invasive early detection of breast cancer. Breast Cancer Res Treat. 2015;154(2):423-34. https://doi.org/10.1007/s10549-015-3591-0.

31. Zhao Y, Pogue Al, Lukiw WJ. MicroRNA (miRNA) signaling in the human CNS in sporadic Alzheimer's disease (AD)-novel and unique pathological features. Int J Mol Sci. 2015;16(12):30105-16. https://doi.org/10.3390/ijms161226223.

32. Qiu L, Tan EK, Zeng L. microRNAs and Neurodegenerative Diseases. In: Santulli G, editor. MicroRNA: Medical Evidence: From Molecular Biology to Clinical Practice: Cham, Springer International Publishing; 2015. p. 85-105. https://doi.org/10.1007/978-3-319-22671-2_6.

33. Serafini G, Pompili M, Hansen KF, et al. The involvement of MicroRNAs in major depression, suicidal behavior, and related disorders: a focus on miR185 and miR-491-3p. Cell Mol Neurobiol. 2014;34(1):17-30. https://doi.org/ 10.1007/s10571-013-9997-5.

34. Issler $\mathrm{O}$, Chen $\mathrm{A}$. Determining the role of microRNAs in psychiatric disorders. Nat Rev Neurosci. 2015;16(4):201-12.

35. Serafini G, Pompili M, Innamorati M, et al. The role of microRNAs in synaptic plasticity, major affective disorders and suicidal behavior. Neurosci Res. 2012; 73(3):179-90. https://doi.org/10.1016/..neures.2012.04.001.

36. Németh N, Kovács-Nagy R, Székely A, Sasvári-Székely M, Rónai Z. Association of Impulsivity and Polymorphic MicroRNA-641 target sites in the SNAP-25 gene. PLoS One. 2014;8(12):1-6. https://doi.org/10.1371/journal.pone.0084207.

37. Rahman OA, Sasvari-Szekely M, Szekely A, Faludi G, Guttman A, Nemoda Z. Analysis of a polymorphic microRNA target site in the purinergic receptor P2RX7 gene. Electrophoresis. 2010;31(11):1790-5. https://doi.org/10.1002/elps.200900664.

38. Fujiwara-lgarashi $\mathrm{A}$, Igarashi $\mathrm{H}$, Mizutani $\mathrm{N}$, et al. Expression profile of circulating serum microRNAs in dogs with lymphoma. Aust Vet J. 2015; 205(2):317-21. https://doi.org/10.1016/j.tvjl.2015.04.029.

39. Zhao F-R, Su S, Zhou D-H, et al. Comparative analysis of microRNAs from the lungs and trachea of dogs (Canis familiaris) infected with canine influenza virus. Infect Genet Evol. 2014;21:367-74. https://doi.org/10.1016/j.meegid.2013.11.019.

40. Jeanson-Leh L, Lameth J, Krimi S, et al. Serum Profiling Identifies Novel Muscle miRNA and Cardiomyopathy-Related miRNA Biomarkers in Golden Retriever Muscular Dystrophy Dogs and Duchenne Muscular Dystrophy Patients. Am J Pathol. 2014;184(11):2885-98. https://doi.org/10.1016/j.ajpath.2014.07.021.

41. Hoeppner MP, Lundquist A, Pirun M, et al. An improved canine genome and a comprehensive catalogue of coding genes and non-coding transcripts. PLoS One. 2014;9(3). https://doi.org/10.1371/journal.pone.0091172.

42. Penso-Dolfin L, Swofford R, Johnson J, et al. An improved microRNA annotation of the canine genome. PLoS One. 2016;11(4):1-18. https://doi. org/10.1371/journal.pone.0153453.

43. Kehl T, Backes $C$, Kern F, et al. About miRNAs, miRNA seeds, target genes and target pathways. Oncotarget. 2017;8(63):107167-75. https://doi.org/10. 18632/oncotarget.22363.

44. Madden SF, Carpenter SB, Jeffery IB, et al. Detecting microRNA activity from gene expression data. BMC Bioinformatics. 2010;11:257. https://doi.org/10. 1186/1471-2105-11-257.

45. Elek Z, Németh N, Nagy G, et al. Micro-RNA binding site polymorphisms in the WFS1 gene are risk factors of diabetes mellitus. PLoS One. 2015;10(10): 1-17. https://doi.org/10.1371/journal.pone.0139519.

46. Borchelt PL. Aggressive behavior of dogs kept as companion animals: classification and influence of sex, reproductive status and breed. Appl Anim Ethol. 1983;10(1-2):45-61. https://doi.org/10.1016/0304-3762(83)90111-6.

47. Perez-Guisado J, Munoz-Serrano A. Factors Linked to Dominance Aggression in Dogs. J Anim Vet Adv. 8:336-42.

48. Mao J, Hu Y, Ruan L, Ji Y, Lou Z. Role of endoplasmic reticulum stress in depression (review). Mol Med Rep. 2019. https://doi.org/10.3892/mmr.2019.10789.

\section{Publisher's Note}

Springer Nature remains neutral with regard to jurisdictional claims in published maps and institutional affiliations.

\section{Ready to submit your research? Choose BMC and benefit from}

- fast, convenient online submission

- thorough peer review by experienced researchers in your field

- rapid publication on acceptance

- support for research data, including large and complex data types

- gold Open Access which fosters wider collaboration and increased citations

- maximum visibility for your research: over $100 \mathrm{M}$ website views per year

At $\mathrm{BMC}$, research is always in progress.

Learn more biomedcentral.com/submissions 